\title{
Editorial: Sensory Categories
}

\section{Yasmina Jraissati $^{1}$}

Published online: 2 August 2019

(C) Springer Nature B.V. 2019

Are whales fish or mammals? Though the answer seems obvious today, it was not the case over a century ago:

\begin{abstract}
"The grounds upon which Linnaeus would fain have banished the whales from the waters, he stated as follows: 'On account of their warm bilocular heart, their lungs, their movable eyelids, their hollow ears, penem intrantem feminam mammis lactantem" (...) I submitted all this to my friends Simeon Macey and Charley Coffin, of Nantucket, both messmates of mine in a certain voyage, and they united in the opinion that the reasons set forth were altogether insufficient (...). Be it known that, waiving all argument, I take the good old-fashioned ground that the whale is a fish, and call upon holy Jonah to back me." (Melville, Moby-Dick or The Whale, 1851, Ch. XXII, "Cetology", p.131)
\end{abstract}

Whether a whale is categorized as a fish or a mammal is not a trivial terminological question. The way we categorize a given item determines the way in which we understand and predict its behavior. The extent to which categorization determines the way we relate to members of the category is debated. Whorf famously argued that depending on the way a given linguistic community categorizes snow, or depending on the way it categorizes time, members of the group would relate to snow and time differently (Whorf 1940; Whorf 1956).

The consequences of cross-cultural differences in categorization, or of shifts in category extensions is a question that also arises in sensory categorization more specifically. There are cross-cultural disparities in the way we name and categorize some sensory experiences, suggesting that we represent them differently. Do we experience them differently as well? Do we experience things according to how we name them? Take the taste category "umami". Though tasted daily, this fifth so-called primary taste (along with bitter, sweet, salty and sour) remained unknown and unnamed until a Japanese researcher, discovered

Yasmina Jraissati

yasmina.jraissati@gmail.com

1 American University of Beirut, Beirut, Lebanon 
an umami receptor in the early twentieth century (Lindemann et al. 2002). Spontaneously, English speakers have a tendency to use the quadripartite classification system (bitter, sweet, salty and sour. O'Mahony and Ishii 1986). With the introduction of "umami" however, and its recent gradually wider public recognition in Europe, people have started distinguishing between umami and salty, and even using correctly the term "umami", though still at relatively low rates. Does this mean that people now perceive something they didn't before, suggesting a top-down modulation of perception by language, or rather that the use of the term "umami" informs their perceptual decision when they identify the taste they are experiencing?

Categories are considered the grounding blocks of cognition (Harnad 2005) yet there are surprisingly many fundamental questions left unanswered in the study of categorization. As perceiving agents, we are informed by the state of the world through our sensory modalities. These modalities act as transducers in a way, transforming various forms of energy (such as electromagnetic radiations) or chemical compounds (molecules) into sensations (light and sound, or smell and flavor respectively). We are exposed to various forms of input, constantly, yet our cognitive relation to these sensations is to an important extent organized. We do not relate to sensations as individual events of a particular character, but rather as instances of categories that are represented in our minds. We are able to communicate about sensations, reflect upon them, remember them, most often identify them and even label them. We are only able to do so because we group different sensations into categories. Thus, categories seem critical to our cognitive life. Where do they come from? How are they formed?

For decades (to consider only more recent discussions), the literature was polarized and the debate crystalized around a nature vs. nurture dichotomy. On the nurture side, the relationship of language to categorization was extensively studied, and researchers have looked at both the role of language in categorizing sensations, and conversely, the possible "top-down" influence of language on perception. On the nature side, various possible mechanisms, perceptual and cognitive, have been looked into. Recently however, several models were put forward that indicate the need to overcome too simplistic an opposition between the roles of biology and of language and culture, leading in turn to new questions and challenges.

To examine sensory categorization mechanisms, vision, and more specifically, color vision, has been by far the most studied modality. The implicit assumption seems to be that findings in color / vision would generalize to other sense modalities. However, while there are some commonalities, there also seems to be telling differences.

This special issue aims to showcase the current state of the research on sensory categorization, which unavoidably tends to focus on the case of color / vision, while tackling some of these fundamental unanswered questions. The latter can be organized under three main headers: (1) Where do categories come from? (2) Is there top-down modulation of perception by lexical categories? (3) When it comes to sensory categories, can findings about one modality be generalized to other modalities? In what follows, these questions are considered in turn. 


\title{
1 Where Do these Categories Come from?
}

\subsection{Rationalism Vs. Empiricism}

The question of the origin of ideas (or concepts) is not new to the philosophy tradition, which is marked by a rationalist / empiricist debate (see Markie 2017, for a useful overview). According to rationalists, some of our concepts cannot have been gained by experience. The latter simply makes our grasping them possible. While Locke famously argues that the mind is a blank tablet on which experience writes, Leibniz objects that the mind is rather a block of marble, which, with its inherent veins will determine the shapes that can be sculpted. Locke claimed that someone who had not tasted a pineapple could not know its flavor, arguing that sensory "ideas" could only be acquired by experience:

"It will be granted easily, that if a child were kept in a place where he never saw any other but black and white till he were a man, he would have no more ideas of scarlet or green, than he that from his childhood never tasted an oyster, or a pineapple, has of those particular relishes." (Locke 1689, §6, Ch 1, Book II)

But for others, things are not so simple. Hume, for example, an empiricist himself, raises an interesting puzzle:

\begin{abstract}
"Suppose therefore a person to have enjoyed his sight for thirty years and to have become perfectly acquainted with colors of all kinds, except one particular shade of blue, for instance, which it never has been his fortune to meet with; let all the different shades of that color, except that single one, be placed before him, descending gradually from the deepest to the lightest, it is plain that he will perceive a blank where that shade is wanting and will be sensible that there is a greater distance in that place between the contiguous colors than in any other. Now I ask whether it be possible for him, from his own imagination, to supply this deficiency and raise up to himself the idea of that particular shade, though it had never been conveyed to him by his senses? I believe there are but few will be of the opinion that he can" (Hume 1748, Section II, pp. 29-30)"
\end{abstract}

Hume's puzzle suggests that our way of relating to colors and to their similarity relations is structured by more than experience. While we clearly need experience to know what blue looks like, and what pineapple tastes like, something independent of experience seems to govern these sensations, and structure them, at least in the case of color (more on this specific point in Section 3).

Note how this interpretation of Hume distinguishes his position from Leibniz's: While Hume's suggestion indicates that something in the way we represent color, independently of experience, governs similarity relations, Leibniz, on the other hand, does not seem to only have cognitive capacities in mind when he refers to the veins in the block of marble. For example, his take on Molyneux's question suggests that independently of the (tactile or visual) nature of the "image" one might acquire from 
experience, there is an "exact idea" of what a cube and a sphere are, which is provided by reason - though of course aided to some extent by experience. ${ }^{1}$

Hume's take on his puzzle brings him closer to the contemporary discussion on the origin of "ideas", or more directly of interest here, of categories. The contemporary discussion indeed takes on a slightly different flavor from the empiricist / rationalist debate, for the question is not whether categories are innate or acquired. In the cognitivist tradition, the question is rather: Given the richness of the sensory input, what is the nature of the organizing principles, granting that these are not purely physical (i.e. "in the world"), or physiological (i.e. "in the mind"), see Kay and McDaniel 1978)? In the case of color, often used as a paradigm case, the question therefore became: Assuming the continuous physical nature of color, what factors are responsible for our drawing the boundaries where we do? Are these factors biological, and innate, or are they cultural or linguistic, and therefore acquired? In the nature vs. nurture contemporary discussion on the origin of categories, both sides agree with Hume: there is something structurally determined in the way we relate to color similarities. The question is not whether we can represent the missing shade of blue despite not experiencing it, but rather: Where does this idea of "blue" come from in the first place? Specifically: What makes us decide that these shades should go together in the same category (e.g. blue), and why should an adjacent shade belong to a different category (e.g. green)?

What we could arguably consider to be the contemporary formulation of the rationalist / empiricist debate is surprisingly recent. Although interest in color categorization in its present form goes back to at least the nineteenth century, it is only around the middle of the 20th that the question was formulated with more precision. The previous discussion was indeed obscured by false nativist assumptions.

Starting with Gladstone's (Gladstone 1858) work on Homeric writings, the argument in parts of the literature was that the blatant absence of some color terms in some ancient languages was evidence of the fact that the corresponding populations did not perceive these colors. So for example, the absence of the word "blue" in Homer's writings and in the ancient Veda hymns (Geiger 1880), or in the languages of the populations of the Murray Island in the Torres Straits (observed at the turn of the twentieth century, Rivers 1901), was evidence that these populations did not perceive the color blue. The assumption seemed then to be that perceiving blue necessarily leads to having the idea of blue. For these thinkers, the capacity to perceive a given color is sufficient for this color to be represented in the lexicon. Or more specifically: The color blue is necessarily represented in the lexicon, and that lexical representation of the concept corresponds to the understanding of "blue" in English. This argument makes a strong nativist assumption, according to which color concepts go hand in hand with color experience. Although it is not denied that experience is required for someone to have a color concept, the latter is assumed to be acquired necessarily, and furthermore

\footnotetext{
${ }^{1}$ Molyneux's problem, notoriously tackled by Locke in his Essay (1689), is the following: Take a man born blind, who knows the difference between a cube and a sphere by touch. If this man were to regain sight, would he be able, at first sight, to distinguish the sphere from the cube? Empiricists such as Locke have answered this question negatively, arguing that the visual idea of a cube and a sphere needs to be acquired by visual experience. Whereas rationalists like Leibniz contend that independently of visual or tactile experience are innate exact ideas of a sphere and a cube, which enable the newly sighted man to visually recognize the sphere and cube. Hume's puzzle regarding the shade of blue was published almost a century later.
} 
to correspond to the English lexical categorization. In that tradition, it was simply unthinkable that the experience of the color blue might not be represented in language, and furthermore, that it be categorized differently than in English.

Cross-cultural comparisons, as practiced and supported by Boas for example (Boas 1938) starting in the late nineteenth century, however showed that the same color experiences could be categorized and named differently across cultures. This observation of cross-cultural disparity separates the experience of color from its representation, and makes room for the question of the origin of color categories to be raised. The subsequent discussion on the origin of color categories, is in consequence much more precise. Acknowledging cross-cultural differences, the twentieth century literature also assumes that the human experience of color being (mostly) the same, the resulting cross-cultural disparities in color categorization must have a different source. Thus, this modern version of the question of the origin of concepts, as applied to the case of color, no longer assumes that color experience and color representation go hand in hand, and nativism no longer concerns the categories themselves, but rather the factors that shape them.

Before we proceed with contemporary attempts to answer the question of the origin of concepts and categories, a terminological and conceptual distinction is required. "Concepts" and "categories" have been used interchangeably so far. These notions are not equivalent, but are usually assumed to be related in the following way: Concepts are representations that guide categorization. It is because I have the concept of a chair that I am able to sort and group various forms of seats under this label, excluding for example stools and sofas that, while they are seats, are different from chairs. Accordingly, concepts are representations in the mind, while categories are groups of items that are in the world (Gärdenfors 2018, this issue; Smith and Medin 1981). Note however that categorization has a metaphysical side, focusing on the conditions that make a given item an instance of the category, and an epistemological side, focusing on how an agent decides whether that item is an instance of the category. Metaphysical categories may not be required in all aspects of categorization and concept use: Smith (1989) argues that we may communicate about the concept gold without having the same concept but rather sharing similar mental contents such as properties that we use to identify gold.

\subsection{The Basic Color Terms Theory}

As mentioned, the cognitive science literature on the origin of sensory categories is dominated by the case of color. The fact that vision is a widely studied sensory modality on one hand, and the fact that color can be physically described as a continuum of electromagnetic radiations on the other (raising the question of how and why we draw the boundaries the way we do), both contribute to the case of color being so central to this question. Whether findings in color can generalize to other sensory modalities is an important question that will be tackled in Section 3. Meanwhile, it seems widely assumed, and to some extent rightly so, that the groundbreaking work in color can be seen as leading the way to a more general understanding of the relationship between sensory experience and cognition.

Though they were not the first to tackle the issue of the origin of categories in a modern way (see for example Brown and Lenneberg 1954; Lenneberg and Roberts 1956), the question of the factors underlying sensory categorization is tightly connected 
to Berlin and Kay's notorious "Basic color terms theory", first presented in a monograph (1969). To this day, any paper discussing sensory categorization, and especially color categorization, from any angle, refers to this seminal work. Berlin and Kay's theory offers two major (though to some extent controversial) insights: 1) we may use many color expressions and terms to refer to our color experience, but only some of these expressions are "basic"; 2) when considering only such basic color terms, it then appears that the cross-cultural difference is evolutionarily constrained, in the sense that these basic color terms are universal, but that their occurrence in a language depends on how many terms the language has. Thus, the difference between say Berinmo, Papua New Guinea (Roberson et al. 2000) and English, is that these languages have reached different lexical evolutionary stages. Berinmo features five terms, while English features eleven. However, as more terms emerge in Berinmo, with enough time this lexicon grows increasingly similar to English. In support of this interesting hypothesis is the fact that completely unrelated languages featuring the same number of basic color terms, will also feature similar partitionings of color space. That is, the five categories in these very different lexica have very similar extensions (for a detailed review of the Basic Color Terms theory and the typical misconceptions, see Witzel 2018, this issue).

Of course, the idea of color lexicon evolution is hypothetical, and the notion of "basic color terms" is not as easily definable or intuitive as it may at first seem (Hickerson 1971; Conklin 1973; Lucy 1996; Maffi 1990; Jraissati 2014b). But the theoretical framework offered by the basic color terms theory was fruitful, and one of the many merits of this theory is to have triggered a wide research movement, with a specialized, rich and innovative literature, as well as a passionate debate, opposing on one hand proponents of a so-called "universalistic" view (according to which basic color terms are universal and ultimately determined by perceptual mechanisms), and proponents of a so-called "relativistic" view (according to which basic color terms are not universal and are instead determined by cultural and linguistic factors).

Though quite irreconcilable at first, these two views gradually converged. No common account of color categorization has yet been achieved, but a tacit agreement seems to be that there is more to it than either cultural or biological factors. None of the latter can each on its own account for all the data. More interestingly, a few altogether different approaches have been explored.

\subsection{Beyond the Nature Vs. Nurture Dichotomy}

The first noteworthy attempt to overcome the narrow boundaries imposed by the traditional debate makes critical use of the notion of "optimality" (Regier et al. 2007). "Optimality" here is the idea that a category is determined by which members are maximally similar to each other and maximally dissimilar to members of other categories. If humans are endowed with such a capacity to optimally categorize, and provided the color space were irregular, then universal categorization would follow. That is, if our sensitivity to color varies across the spectrum, and is not constant, then the similarity relations between colors would vary across the spectrum too, leading, when combined to optimal categorization, to universal categories. It turns out that our sensitivity thresholds do vary across the spectrum. Regier et al's (2007) hypothesis was tested with artifical systems. Ultimately, this paper is taken to show by its authors that while some perceptual factors are bound to play a role in the way we categorize, 
such factors do not determine categorization in a rigid way, and allow for some flexibility thereby making room for external factors such as cultural interests or environment. $^{2}$

A series of recent studies has indeed shown that the relationship between perception and lexical categorization was only loose. (Witzel 2018; see also Witzel and Gegenfurtner 2013; Witzel and Gegenfurtner 2015; Witzel and Gegenfurtner 2018). Testing just noticeable difference thresholds across an isoluminant hue circle in DKL space (for "Derrington, Krauskopf and Lennie", which, unlike other spaces that have been used in the above mentioned studies, represents sensitivities of the actual opponent mechanisms in humans and is therefore most adequate to test for sensitivity thresholds), these studies have shown that two lexical boundaries coincide exactly with sharp dips in sensitivity thresholds, namely the lexical "blue"/ "green", and "pink" / "yellow" boundaries. ${ }^{3}$ However, not all lexical boundaries correspond to sensitivity dips. This strongly suggests that there is more at play in lexical categorization than varying sensitivity thresholds.

Beyond perceptual mechanisms, one must not forget that lexical terms are also meant to be used for linguistic exchanges within a certain community. In line with the idea that the convention by which linguistic meaning is fixed results from an equilibrium achieved in a coordination game (Lewis 1969), several game-theoretic approaches were developed and applied to natural kinds. Such concepts consist of sets of multiple items that are related by similarity relations, or an underlying similarity structure (Park et al. 2018, this issue). A seminal study by (Steels and Belpaeme 2005) had shown that communication constraints favor the emergence of certain (basic) color terms rather than others. It appears that the use of small sized populations (between 30 to 100 artificial agents), and the use of a small number of discriminable colors in training are factors that may account for the near optimal solutions found (Komarova et al. 2007). However, size is not the only population factor: The introduction of new naïve members, and the departure of the same number of members also contribute to "optimal equilibrium" - where, in this context, optimality is understood as the maximal number of agreeing categorizations across the population; and where equilibrium is understood as (roughly) maintaining the same naming strategy throughout the continued evolution of the game. Thus Park et al. 2018, this issue show that the birth and death cycle of a population, constant in size, is a factor in reaching optimal equilibrium, that is, leading to a color categorization system that is similar to the one observed in natural languages. They also suggest that some category sizes are more adequate than others and have therefore an evolutionary advantage (too small or diffuse categories, or too large categories are not advantageous). As Park et al. also note, the birth-death cycle in human societies varies with technological development, and incidentally, so does the size of color lexicons: The more technologically developed a society, the larger its color lexicon, and also, the longer the life expectancy of the members of society. Park et al.'s study suggests a

\footnotetext{
2 Though the aim of Regier et al. 2007's paper is to account for cross-cultural variations and regularities by making room for perceptual and cognitive factors to interact with cultural factors, it is not clear that this is what the paper shows (see Jraissati and Douven 2017; and Jraissati 2014a for a discussion).

${ }^{3}$ Because an isoluminant circle was used, no red category was observed at the used luminance level.
} 
link between the lifespan of the population, and the number of color terms. Indeed, varying the lifespan of agents produces changes in the number of categories.

\subsection{From the Origin of Concepts to the Origin of Conceptual Spaces}

In the discussion pertaining to the origin of categories, color spaces, where similarity relations are represented, have become increasingly important. Starting with Berlin and Kay's use of the Munsell system (and Lenneberg and Roberts 1956; Lenneberg 1961 before them), this representation of similarity relations has at first played only an accessory role. The Munsell system initially only provided an adequate reliable and practical tool to test for color naming, as well as represent categories extensions. Gradually, as interest in color space partitioning and category structure grew, so did the importance of similarity relations, and specifically, the various spaces in which they were represented. While it may at first seem that all color appearance spaces are equally valid and the choice to use one rather than another is somewhat arbitrary, it is not unlikely that the Munsell system may have biased some of the results that are today taken for granted by most (see Witzel 2018 , this issue).

The study of sensory (and in particular color) categorization, heavily relies on such spaces to examine category structure and to model categorization (see Park et al. 2018, this issue, for a similar point). The notion of "category structure" is mostly a descriptive one, since it simply means that categories are not just sets of items that fall under the same label. In a structured similarity space, and given a category that is represented as a region of that space, all points that fall within that region represent members of the category. But not all points that fall within that region are members of the category to the same degree. Some members of the category are more representative of the category, they are the category's best examples. Also, the category's best examples always lie at the center of the category.

Prototype theory, the development of which paralleled that of the basic color terms theory, offers a detailed description of category structure, and of the principles that seem to guide it. And for many years, a color category's best examples or color foci (color samples chosen as the most representative of the category by participants) often identified in naming tasks have been conflated with the prototype. The notions of focal color and prototype should not be equated. Despite being close and possibly connected, they nonetheless pertain to different theoretical frameworks: the focal color is the color that is chosen by participants in a color naming study as being most representative of a given category, while the prototype is most representative of a category in virtue of two cognitive categorization principles (cognitive economy and perceived world structure, Rosch 1999). What makes colors focal is a subject of debate: Are they more salient for reasons that are ultimately perceptual (Rosch 1973; Regier et al. 2007)? Are they most representative of the category (Abbott et al. 2016)? Or do they result from the category's extension (see Regier et al. 2005, p.8386; Roberson et al. 2000)? This being said, there is no doubt that color categories are structured, displaying in particular the graded structure so extensively studied in the context of prototype theory. Interestingly, the notion of category structure also has predictive power: Given a focal region and a metric conceptual space, a category's extension can be predicted (Douven et al. 2016). 
According to (Gärdenfors 2000), this "gradedness" of categories can be accounted for by their convexity. Specifically, a conceptual space, such as color space, is a geometric structure that represents quality dimensions (i.e. the qualities by which the various points in the space can be compared). Concepts, or categories, for example "blue", are represented by regions, extending over several points, in the space. Natural categories are convex regions in conceptual space: If $\mathrm{A}$ and $\mathrm{B}$ are members of a given category $\mathrm{X}$, and if $\mathrm{U}$ is between $\mathrm{A}$ and $\mathrm{B}$, then, if $\mathrm{X}$ is convex, $\mathrm{U}$ belongs to the same category $\mathrm{X}$ as $\mathrm{A}$ and $\mathrm{B}$. Thus, in a convex region, some points are located more centrally than others. If that convex region is in a similarity space, the centrality of the point implies that it is similar to the largest number of points within the convex region. This, leads to this point being most representative of the category and prototypical, which in turn leads to gradedness.

Conceptual spaces combined with convexity provide a powerful framework to account for the origin of categories and concepts. The conceptual spaces approach distinguishes between "sensations", as what our senses receive, and "percepts", as interpreted sense data. Mapping sensations onto conceptual spaces is what would turn them into percepts. These conceptual spaces are next partitioned into many convex regions, representing concepts. However, to achieve the bigger goal of accounting for the origin of categories, this promising approach has yet to provide an answer to the following questions: 1) How are categories carved in conceptual spaces, or why are they carved the way they are? And more fundamentally, 2) Where do these conceptual spaces and their dimensions come from? In this issue, Gärdenfors outlines an answer.

A conceptual space is a geometric representation of a given domain. Some dimensions are integral, while others are separable. For example, the pitch of a sound is inseparable from its loudness. Thus two dimensions are integral when a value in one of these dimensions cannot be assigned to an object without a value from another dimension being also assigned. Non-integral dimensions on the other hand are separable, like shape and color. Thus, a domain is a set of integral dimensions that are separable from all other dimensions. The question of the origin of conceptual spaces can therefore be reformulated as follows: Where do domains come from? Gärdenfors conjectures that, early in development, these domains are generated by the human agent using invariants in the perceptual input. Thus, sensory input in early development is sorted into a limited number of general ontological domains. An analysis of perceptual invariants explains why space, objects, and actions are primary domains (as previously suggested in the developmental literature). As they develop, children are able to attend to one dimension of a given domain. The former is then separated and developed into a sub-domain. Thus children go from judgments of similarities in one primary domain (e.g. objects) to judgments of kinds of similarities in what becomes subdomains (e.g. color, size, etc.). Regarding the first question, of how concepts are formed, Gärdenfors relies on the notion of covariation, and the idea that perceptual information is not random, but comes in clusters. A focused sampling results, whereby objects that have properties which have already proven to be connected, are preferentially selected. Thus, the more properties objects have in common, the more similar they will be, and the smaller the size of the cluster they form (for a comparable idea, see Rosch 1999). 


\section{Is there Top-Down Modulation of Perception by Language?}

\subsection{Language and Cognition}

There are thus predictably multiple aspects to the question of the origin of concepts and categories, ranging from perceptual and cognitive factors, to population dynamics, through the structure of our concepts, or of our representations, being determined both by perception, cognition, and regularities in the world. The relation of language to concepts and categories is yet another tricky question. Are all conceptual representations necessarily lexicalized (Malt et al. 2015)? In the early days of the Basic Color Terms theory, the (problematic) implicit claim was that color categories were universals, somewhat preceding lexicalization and waiting to be labeled - this was especially true of the categories corresponding to the "unique hues" (Hering 1964), black, white, yellow, red, blue and green. This is in line with the so-called universalistic idea that color categories are determined by perceptual factors, independently of language and culture. On the other hand, proponents of the so-called relativistic view contend that categories are determined by language use. It is language that shapes categories: The more a term is used in a given community to refer to certain colors, the more this term, along with the extension of the category it refers to, stabilizes. This idea can be traced back to Sapir (1929), according to whom "The world is to a large extent unconsciously built up on the language habits of the group" Sapir 1929, p.209). Thus, conventional use of words is what fixes their references. However, what is exactly meant by the world being "built up" on a community's language habit is subject to interpretation. Sapir's disciple Whorf is often quoted as saying:

"We have the same word for falling snow, snow on the ground, snow packed hard like ice, slushy snow, wind-driven flying snow - whatever the situation may be. To an Eskimo, this all-inclusive word would be almost unthinkable; he would say that falling snow, slushy snow, and so on, are sensuously and operationally different, different things to contend with; he uses different words for them and for other kinds of snow" (Italics added. Whorf 1956, p.216)

The implications of this claim are often taken to be straightforward, but one may wonder: Doesn't English specifically have many categories for different states of snow, as Whorf himself indicates? What then is the critical difference between English and Eskimo supposed to be? Is it simply that Eskimo have different terms to refer to these different categories? And what are the alleged consequences of this difference? Is it that as Eskimos name these categories differently, they consequently have a different perceptual experience of the world - in contrast to English speakers who while they categorize different states of snow do not name them differently (Pullum 1991, but see Regier, Carstensen and Kemp 2016)? It is not clear exactly what Whorf intended to claim, but this is how the modern interpretation of Whorf goes. In this sense, Whorf's claim seems akin to the contemporary notion of "cognitive penetration", according to which higher 
cognitive states, such as beliefs and language, modulate lower processes, such as perception. $^{4}$

Specifically, when it comes to sensory categorization, and to the paradigmatic case of color, the study of "categorical perception" is directly relevant to the cognitive penetration debate, given that it examines whether the way we categorize colors affects our perceptual sensitivity thresholds.

One possible definition of cognitive penetration is offered by Pylyshyn (1999):

"If a system is cognitively penetrable then the function it computes is sensitive, in a semantically coherent way, to the organism's goals and beliefs, that is, it can be altered in a way that bears some logical relation to what the person knows" (Pylyshyn 1999, p.343)

Thus, if linguistic color categories cognitively penetrate color perception, the perceptual function of color processing should be altered by it. This is the thorny heart of the question, as we shall see in the following paragraph.

\title{
2.2 Language and Perception
}

Study of the categorical perception of color goes back to the 1970s', and was inspired by the preceding work on phonemes (Liberman et al. 1957; Liberman et al. 1967; Abramson 1961). The common understanding of categorical perception is well captured by Harnad:

\begin{abstract}
"Equal-sized physical differences between stimuli are perceived as larger or smaller depending on whether the stimuli are in the same category or different ones. Indeed, the effect is not only quantitative but qualitative: A pair of greens of different shades look more like one another than like a shade of yellow (which may be no more different in wave length from one of the greens than the other green is)" (Harnad 1987).
\end{abstract}

Quantitatively, categorical perception is assessed in discrimination tasks. The reasoning is as follows: If sensitivity thresholds are decreased at category boundaries, then discrimination performance should increase between cross-category color samples in comparison to within-category samples. Thus, if an improved discrimination performance can be observed at lexical category boundary, then this would be an indication of a warping of the color space by language. Many behavioral studies have shown that, indeed, discrimination performance was improved between cross-category color samples, as accuracy was higher, and response times lower.

\footnotetext{
${ }^{4}$ Whether Whorf's claims were in fact closer to the theory-ladedness of observation than to cognitive penetration, granting that these two thesis are not equivalent (see Prychitko, E., "Dissociating the Cognitive Penetrability of Perception and the Theory-Ladenness of Observation", Paper presented in Turin, "Cognitive penetration" workshop 2018), is a question worth exploring. Whorf was indeed most interested in crosscultural disparities in the "scientific" or theoretical descriptions of the world: "We are thus introduced to a new principle of relativity, which holds that all observers are not led by the same physical evidence to the same picture of the universe", Whorf 1956.
} 
However, the reasoning behind these studies offered as an assessment of categorical perception is fallacious. All these studies show is that discrimination performance is improved at category boundary. These studies do not show that the discrimination performance is improved because of an increased sensitivity at the lexical boundary. In other words, that the observed discrimination performance can be accounted for by categorical "perception" is not shown. All that is shown is a categorical "effect". Whether the effect is perceptual or not still needs to be determined.

Thus, the nature of the role of language in categorical effects needs further examination: Does language modulate the perceptual function, or does it simply inform judgment during discrimination tasks? Masking tasks were introduced in studies of categorical effects to answer this specific question. Take the visual search task, one among several possible paradigms used to measure discrimination performance: A limited number of color patches, typically 6 or 8 , are presented in a circle with a central fixation point. All the patches (the distractors) are of the same color except one (the target). The target can be either of the same category as the distractors, or of a different category. In both cases, the physical difference between the target and the distractors is the same. So if there are two Munsell hue steps between the blue distractors and the (different) blue target, there will also be two Munsell hue steps between the blue distractors and the green target. ${ }^{5}$ The participant is asked to indicate, as quickly as possible whether the target is in the left or right half of the circle. We find that when the target belongs to a different category, participants are significantly faster at localizing it. So in cross-cultural comparisons, different behaviors are observed at the same boundary depending on whether the boundary is instantiated in the lexicon. A widely cited study is that of Winawer et al. (Winawer et al. 2007) on Russian, where, unlike in English, there are two blue categories, one for light blue and one for dark blue. Winawer et al. observe a significant difference between the Russian performance in the cross-category (light blue / dark blue) condition compared to the within-category condition. On the other hand no difference between these two conditions is observed in English speakers (for other studies of categorical effects, perhaps with more significant differences, see for example Siok et al. 2009; Gilbert et al. 2006; Roberson et al. 2008, where categorical effects are measured using reaction times, or Roberson and Davidoff 2000 where categorical effects are measured using accuracy).

However, this cross-category advantage is disrupted when a verbal masking task is introduced. That is, before the screen of the visual search task is displayed, the participant is shown a screen with a random string of numbers (or words, or letters) that she is asked to remember. After the discrimination task, a screen with several strings of numbers (or words, or letters) is presented, and the participant needs to say which of these alternatives she was presented at the beginning of the block. In order to be able to identify the string of numbers at the end, the participant needs to commit it to memory throughout the discrimination task. What Winawer et al. (Winawer et al. 2007; also see Roberson and Davidoff 2000; also see Hanley and Roberson 2011) show is that the cross-category advantage disappears when a verbal masking task is involved. However, this cross-category advantage does not disappear when a visual masking task

\footnotetext{
${ }^{5}$ Wether Munsell hue steps count as a measure of "physical" difference is debatable, given that the Munsell system is a color appearance space, based on human judgments of perceptual distance. More on this point in footnote 6, and in Witzel 2018, this issue.
} 
is involved - that is: participants are asked to commit a visual pattern to memory at the beginning of the task, and then asked to identify the pattern they were first shown among several alternatives at the end.

Thus, it is not the introduction of any masking task that disrupts the discrimination performance. Only the verbal, not the visual, masking task has this effect. The verbal masking task was designed so the participants could not access any words, apart from the ones they had to commit to memory, while discriminating. Presumably, then, the verbal masking task prevented the access to the color lexicon. This would suggest that an online access to language is required for the cross-category advantage to manifest itself during discrimination. These results speak in favor of the "lexical strategy" account, according to which the cross-category advantage in discrimination does not result from a modulation of perception by language. Rather, perception and language would simultaneously inform the discrimination decision (Mitterer et al. 2009). According to the definition of cognitive penetration above, lexical categories do not affect the perceptual function of color vision processing, but merely inform the higher cognitive decision making process during discrimination, thereby making it faster. As a result, it would indeed be inaccurate to speak of categorical "perception". Some have suggested to use the notion of "categorical facilitation" (Witzel 2018, this issue). ${ }^{6}$

When it comes to investigating categorical effects, one last general point, is the often neglected critical question of stimuli control. As mentioned above, if the point of these studies is to measure how lexicon might affect perception in discrimination tasks, then it is crucial that the stimuli presented as belonging to the same category or belonging to different categories be perceptually equidistant, for every participant. However, most studies of categorical perception do not offer this kind of control (see a detailed discussion in Witzel 2018, this issue).

Are low-level stages of visual processing "encapsulated" then, as some have claimed (Pylyshyn 1999; Raftopoulos 2001; Raftopoulos 2017)? Clearly, part of the answer to this question depends on how one defines "perception", and what one considers to be high-level cognitive states. Traditionally, conceptual representations and categories have been considered high-level. What if, different from conceptual representations and categories there were other kinds of possibly low-level representations? Deroy (2019, this issue) examines this possibility.

The notion that linguistic categories might affect perceptual processing presupposes that categorization depends on the concepts one possesses: categorizing would simply be the application of a concept to a preexisting representation or to an instance in the

\footnotetext{
${ }^{6}$ Recently, categorical effects were also investigated using Evoked Response Potentials. This neurological measure, unlike the most widespread behavioral measures discussed here, could possibly tell without ambiguity whether the nature of the effect is perceptual or post-perceptual, based on the time, after stimulus onset, at which certain waveforms are observed. See for example (Fonteneau and Davidoff 2007; Holmes et al. 2009; Thierry et al. 2009). However, most these results are not convincing, as the timings do not favor a perceptual interpretation. Holmes et al. 2009 study does show a categorical effect signature at $90 \mathrm{~ms}$ after stimulus onset, which is usually considered to be of perceptual nature. However, Holmes et al. only examine one lexical boundary, the blue/green boundary, which may well be of perceptual, and not lexical, nature (Franklin et al. 2005; Clifford et al. 2009; Witzel and Gegenfurtner 2013). Also, Holmes et al. (2009) results, were not replicated when using the DKL color space instead of color appearance spaces (He et al. 2014), implying that the perceptual difference at the blue / green boundary may have been incorporated in color appearance spaces such as the one used by Holmes et al. See Siuda-Krzywicka, Boros, Bartolomeo and Witzel 2019, in press, Section 2 for a review.
} 
world. Deroy's concern starts with the observation that as constituents of thought, concepts should be deployed in a deliberate and controlled way; it should also be possible to consciously reflect on the use of concepts; finally, excluding cases of vagueness, they are definable through a set of sufficient and/or necessary conditions. In contrast, perceptual categorization is highly automatic, that is, it is independent of voluntary control and inaccessible to awareness. In addition, there are reasons to believe that the sorting involved in categorization should be probabilistic and quickly updated. Taking the case of categorical effects in color, Deroy argues on the basis of results such as Fonteneau and Davidoff's (2007) recordings of Event-Related Potentials (ERPs) in a paradigm meant to examine the perceptual nature of categorical effects, that even if the response after stimulus onset is too slow to qualify as "perceptual" (120 ms) it is still too fast to be voluntary. It could therefore qualify as automatic and independent of control. Deroy also uses the case of racial categorization, relying both on a seminal paper by Levin and Banaji (Levin and Banaji 2006; but also see Firestone and Scholl 2015), and mainly on a study by Travers et al. (Travers et al. unpublished, available at this link: https://psyarxiv.com/je 7j4/), to argue that even when people are made aware of possible racial biases, the race-based categorical effect persists, suggesting that it is not dependent on executive control. Thus, Deroy distinguishes between categories, which are characterized by their graded structure, and these simpler automatic sorting principles.

Deroy's paper thus explores the interesting possibility of abstract representations that would however be low-level (to the extent that the low-level / highlevel distinction applies) and thereby different from concepts. It also raises the question of the way in which these sorting principles are learned and the differences implied: Are these sorting principles learned in a rule-based matter, or in an exposure-based manner? Clearly, if these sorting principles are learned based on exposure, then this approach would make room for automatic categorical effects, without resorting to cognitive penetration, or any form of topdown modulation of perception by concepts.

\section{Can Findings in One Modality Be Generalized to Other Modalities?}

\subsection{Color as a Case Study}

The desire to extend findings in one modality to others is understandable, and many studies that concern or rely on mainly color and vision explicitly express this wishful thought (see the papers of respectively Gärdenfors; Deroy; Park et al., only to refer to contributions in this special issue). The supposition that there must be some commonalities in sensory categorization across modalities seems natural. After all, across all sensory experiences, the starting points are comparable, and so are the outcomes: Starting with various forms of energy that they experience differently, humans obtain more or less organized representations of these sensations that are critical to their cognitive life. The question is not simply whether (here) vision-based findings and models are generalizable, but also how? At what level of detail should we look for commonalities, at what level of description? And most importantly: What are the differences? How are they telling? 
For example, using a parallel with visual perception, Montemayor (2019) argues in favor of a comparable general architecture in time perception, where an encapsulated low-level system guarantees the reliability of the information, and a permeable highlevel system interacts with other streams of information processing. Does this imply that all perceptual systems at low-levels of processing are encapsulated? But apart from the issue of top-down modulation of perception by high-level representations, there is the question of categories themselves: Do they result from an interaction of biological and cultural factors, as seems to be the case in color? In what way? Can we expect them to be graded, and to feature a foci or best example? Do they relate to language in a similar way? That is: are all sensory categories lexicalized? Are they lexicalized using abstract terms? Or does language shape these categories to some extent?

The case of odor categorization has been recently debated, and turns out to be most informative for at least two reasons. First, there was, until recently, a widespread agreement, that odor sensations could not be systematically organized, often based on the contrasting case of color:

"In the domain of colours (...) the terms are hierarchically organized (...) In the domain of smells, there is nothing similar; the only possible classification is that of their causes" (Sperber 1975, p.116).

Second, in most odor naming studies, the empirical approach has been quite comparable to color: Ethnologists, anthropologists, or linguists, have sought to identify an odor lexicon that, as in the case of color, was consensual and abstract. As in color, participants were either asked to name odor stimuli, describe them, or to spontaneously list them, or such terms were identified in relevant corpuses. As I explain in the following paragraphs, the quest for a systematic organization and for abstract labels, which in some respects seems borrowed from color vision, may have obscured crucial aspects of odor cognition.

\subsection{Odor: The Limits of the Color Paradigm}

Naming an odor is not straightforward. Even if humans are able to discriminate odors (Shepherd 2004) and to describe them, we usually tend to identify the source of the odor (e.g. the smell of petrol) or to express the effect a given odor has on us (e.g. unpleasant). As we have seen: language and categorization have an intricate relationship. In the case of odor, it is often assumed that because we lack an abstract odor lexicon comparable to color, we also lack the corresponding categories. We are indeed not good at identifying, remembering or detecting similarities between odors, independently of information about their sources (Cain 1982; Engen 1987; Dubois 2000; Kurtz et al. 2000; Demattè et al. 2009).

Recently, some have claimed that when it comes to naming and categorizing odor sensations, there might be differences that are in fact cross-cultural (Levinson and Majid 2014; Wnuk and Majid 2014; Majid and Burenhult 2014), rather than cognitive and perceptual (Lorig 1999; Walla et al. 2003). As the debate in odor categorization and naming seems set to take the path of a nature vs. nurture contrast, some have recommended against this dichotomy (Olofsson and Gottfried 2015; Olofsson and Wilson 2018). 
While it is true that several studies of odor naming in various part of the world suggest that an abstract odor lexicon comparable to color exists (Mouélé 1997; Shepard 1992; Enríquez 2004; Wnuk and Majid 2014; Majid and Burenhult 2014; Wawrzyniak 2016) this seeming likeness to color is misleading. In several important respects, it is only superficial, for at least two reasons. First, olfactory experience is extremely rich and complex: With over 300 receptors, and single odorants being able to bind with several receptor subtypes, and conversely a single receptor being able to bind with multiple different odorants (Malnic et al. 1999), there are countless numbers of new component combinations that can be perceived. Also, the same component is experienced differently across time, and as a result of experience and context. Finally, memory for odors is shown to be different than visual or sound memory, with smells most often remembered in episodic memory (Koster et al. 2002). Thus, the physical nature of the stimuli combined with the nature of receptors, and our limited memory and cognitive capacities, lead to odor not being organized in a structured whole. The history of odor science illustrates this fact, with its many inconclusive attempts to offer a structured multi-dimensional space of olfactory experience (Kaeppler and Mueller 2013). It is therefore difficult to contend, as the literature implies, that the odor terms and categories reported in the ethnographic and psycholinguistic literature range over all possible olfactory experiences, as it does in the case of color.

The other reason why it seems unlikely that the cited languages may be said to feature an abstract odor lexicon comparable to color is simply that reported odor terms are not exactly abstract. While in most cases they are shown to be consensual and monolexemic, these terms usually range over two dimensions: pleasant / unpleasant, and toxic / non-toxic (Wnuk and Majid 2014; Haddad et al. 2010). The first dimension is hedonic, and concerns the effect of the odor on the perceiver, while the second dimension concerns the odor source: Neither of these two dimensions concerns the properties of the odor itself.

The comparison to color, in the case of odor, may have prevented our grasp of some important characteristics of this modality: the absence of a "total" odor space that includes all possible olfactory experience, and the absence of abstract odor terms are in one sense connected. A conceptual space rests on the extraction of dimensions, which are none but the abstract properties that characterize all the experiences represented in that space. The absence of such a space indicates the absence of such dimensions. In turn, the absence of abstract dimensions common to all odor experiences, suggest that there may not be abstract odor lexical categories in the expected sense. Or conversely, that what we usually consider as being an abstract property is irrelevant in the context of odor.

Indeed, there seems to be consensual lexical categories in some communities, for example perfumers and wine experts. What characterizes the odor lexica of these communities is first, that they range over a determined sub-set of odors (e.g. fragrances and wines, respectively), and second, that the highly consensual lexicon used is typically not abstract (e.g. "this wine has violet and leather aromas"). Even if, in the case of wine, a voluntary effort was deployed to create such a lexicon (Noble et al. 1984), the fact remains that this lexicon is in use and has stabilized within the wine experts' community (Solomon 1990). That this is also the case in the languages said to have an abstract odor lexicon cannot be excluded.

Thus, in at least two respects, it could be argued that color has set the wrong expectations (for a comparable point, see Barwich 2019). First, there can be an odor 
taxonomy, except that lexical odor categorization would take place over a determined sub-set of odors, versus a global odor space as expected on the basis of the color example. Second, regarding the presence or absence of abstract odor lexicon, perhaps unlike color, it may be part of the function of odor to remain attached to the source (see Köster et al., 2014 for a similar point): Odor is after all intrinsically about the source of the experience, in that it signals an approach or a retreat from a given object (Yeshurun and Sobel 2010). Taking this observation into consideration questions the reason why odor terms would need to be abstract in the way that color terms are.

In summary, groundbreaking work in color / vision research as to how sensory categorization takes place certainly offers interesting leads for other sensory modalities. We have however seen how crucial the representation of color in a structured similarity space was to account for and model category structure and more generally, categorization; while the mere existence of such a space can be questioned in the case of odor, but also to some extent, in the case of touch (see Yoshida 1968; Hollins et al. 1993; Hollins et al. 2000; Picard et al. 2003, but also Soufflet et al. 2004; Bergmann and Kappers 2006; Guest et al. 2011) sound (Dubois et al. 2006; Berglund and Nilsson 2000; Ellermeier et al. 2004) - in contrast to music (Dubois 2000; but see Pressnitzer et al. 2013, regarding timber) - and even flavor (Erickson 2008). When it comes to representing a sensory experience in a structured similarity space, color might be quite exceptional. This being said, these limitations and differences provide in and of themselves valuable insight, as they draw attention to the question of how sensory categorization differs across modalities, and as a result, the ways in which findings in one modality could generalize to others.

\section{Contributions}

In "From sensations to concepts: A proposal for two learning processes", Peter Gärdenfors offers an answer to the question of the origin of conceptual spaces. These are geometric representations of a given domain, themselves generated by human agents early in development, relying on invariants in the perceptual input. Space, objects and actions are such primary domains.

In "Categorizing without concepts" Ophelia Deroy examines, on the basis of empirical evidence regarding visual experience, the relationship between concepts and categorization. Specifically, perceptual categorization is fast, in some cases involuntary and unconscious, whereas one expects to deploy concepts in a deliberate and controlled way. While concepts may remain necessary for categorization, Deroy opens the possibility that they are not and that sorting principles might in some cases be sufficient.

Regarding why color universals are found across different cultures and languages, Jungkyu Park, Sean Tauber, Kimberly Jameson and Louis Narens explore the role of life and death cycle in "The evolution of shared concepts in changing populations". They find that birth-death mechanism move an established population color naming system toward a more optimal one.

Christoph Witzel's "Misconceptions about color categories" questions some of the central assumptions of the color categorization literature, namely: 1) that color perception is inherently categorical, 2) that English basic color terms correspond to universal categories, 3) that the prototypes of English basic color terms are perceptually salient, and 4) that color category research revolves essentially around the universalism 
/ relativism debate. He takes this opportunity to review the most recent research on these issues.

\section{References}

Abbott, J.T., T.L. Griffiths, and T. Regier. 2016. Focal colors across languages are representative members of color categories. Proceedings of the National Academy of Sciences 113 (40): 11178-11183.

Abramson, A.S. 1961. Identification and discrimination of phonemic tones. The Journal of the Acoustical Society of America 33 (6): 842-842.

Barwich, A.S. 2019. A critique of olfactory objects. Frontiers in Psychology 10: 1337.

Berglund, B., and M. E. Nilsson. 2000. Total annoyance and perceptually discernible noise sources. Proceedings of InterNoise 2000.

Bergmann, T.W.M., and A.M.I. Kappers. 2006. Analysis of haptic perception of materials by multidimensional scaling and physical measurements of roughness and compressibility. Acta Psychologica 121: 1-20.

Berlin, B., and P. Kay. 1969. Basic color terms: Their universality and evolution. California: CLSI Publications.

Boas, F. 1938. The mind of primitive man. New York: The Macmillan Company.

Boroditsky, L. 2011. In Time and number in the brain: Searching for the foundations of mathematical thought, ed. S. Dehaense and E. Brannon. Academic Press: Elsevier.

Brown, R., and E. Lenneberg. 1954. A study in language and cognition. Journal of Abnormal and Social Psychology 49: 454-462.

Cain, W.S. 1982. Odor identification by males and females: Predictions vs performance. Chemical Senses 7 (2): 129-142.

Clifford, A., A. Franklin, I.R. Davies, and A. Holmes. 2009. Electrophysiological markers of categorical perception of color in 7-month old infants. Brain and Cognition 71 (2): 165-172.

Conklin, H.C. 1973. Color categorization. American Anthropologist 75: 931-942.

Demattè, M.L., D. Sanabria, and C. Spence. 2009. Olfactory discrimination: When vision matters? Chemical Senses 34 (2): 103-109.

Deroy, O. 2019. Categorising without concepts. Review of Philosophy and Psychology. https://doi.org/10.1007 /s13164-019-00431-2 (this issue).

Douven, I., S. Wenmackers, Y. Jraissati, and L. Decock. 2016. Measuring graded membership: The case of color. Cognitive Science. https://doi.org/10.1111/cogs.12359.

Dubois, D. 2000. Categories as acts of meaning: The case of categories in olfaction and audition. Cognitive Science Quarterly 1: 35-68.

Dubois, D., C. Guastavino, and M. Raimbault. 2006. A cognitive approach to urban soundscapes: Using verbal data to access everyday life auditory categories. Acta Acustica united with Acustica 92 (6): 865-874.

Ellermeier, W., Zeitler, A., and H. Fastl. (2004). Impact of source identifiability on perceived loudness. ICA 2004, 2, 1491-1494. Kyoto, Japan.

Engen, T. 1987. Remembering odors and their names. American Scientist 75 (5): 497-503.

Enríquez, H. 2004. La categorización de los olores en totonaco. Dimensión Antropológica 30: 103-128.

Erickson, R. 2008. A study of the science of taste: On the origins and influence of the core ideas. Behavioral and Brain Sciences 31 (1): 59-105.

Firestone, C., and B.J. Scholl. 2015. Can you experience `top-down' effects on perception?: The case of race categories and perceived lightness. Psychonomic Bulletin \& Review 22 (3): 694-700.

Fonteneau, E., and J. Davidoff. 2007. Neural correlates of colour categories. Neuroreport 18 (13): 1323-1327.

Franklin, A., M. Pilling, and I. Davies. 2005. The nature of infant color categorization: Evidence from eye movements on a target detection task. Journal of Experimental Child Psychology 91: 227-248.

Gärdenfors, P. 2000. Conceptual spaces : The geometry of thought. Cambridge: MIT Press.

Gärdenfors, P. 2018. From sensations to concepts: A proposal for two learning processes. Review of Philosophy and Psychology. https://doi.org/10.1007/s13164-017-0379-7 (this issue).

Geiger, L. 1880. Contributions to the history of the development of the human race. London: Tubner and Company.

Gilbert, A., T. Regier, P. Kay, and R. Ivry. 2006. Whorf hypothesis is supported in the right visual field but not the left. PNAS 103 (2): 489-494.

Gladstone, W.E. 1858. Studies on Homer and the homeric age. Vol. 3. Oxford: Oxford University Press. 
Guest, S., J.M. Dessirier, A. Mehrabyan, F. McGlone, G. Essick, G. Gescheider, and K. Blot. 2011. The development and validation of sensory and emotional scales of touch perception. Attention, Perception, \& Psychophysics 73 (2): 531-550.

Haddad, R., T. Weiss, R. Khan, B. Nadler, N. Mandairon, M. Bensafi, et al. 2010. Global features of neural activity in the olfactory system form a parallel code that predicts olfactory behavior and perception. Journal of Neuroscience 30 (27): 9017-9026.

Hanley, J.R., and D. Roberson. 2011. Categorical perception effects reflect differences in typicality on withincategory trials. Psychonomic Bulletin \& Review 18 (2): 355-363.

Harnad, S. 1987. Introduction: Psychophysical and cognitive aspects of categorical perception: A critical overview. In Categorical perception: The groundwork of cognition, 1-25. New York: Cambridge University Press.

Harnad, S. 2005. In Handbook on categorization, ed. H. Cohen and C. Lefebvre. Elsevier.

He, X., C. Witzel, L. Forder, A. Clifford, and A. Franklin. 2014. Color categories only affect post-perceptual processes when same- and different-category colors are equally discriminable. Journal of the Optical Society of America 31 (4): A1-A9.

Hering, E. 1964. Outlines of a theory of the light sense. Cambridge: Harvard University Press.

Hickerson, N. 1971. Review of basic color terms : Their universality and evolution. International Journal of Amercian Linguistics 37 (4): 257-270.

Hollins, M., R. Faldowski, S. Rao, and F. Young. 1993. Perceptual dimensions of tactile surface texture: A multidimensional scaling analysis. Perception \& Psychophysics 54: 697-705.

Hollins, M., S. Bensmaïa, K. Karlof, and F. Young. 2000. Individual differences in perceptual space for tactile textures: Evidence from multidimensional scaling. Perception \& Psychophysics 62: 1534-1544.

Holmes, A., A. Franklin, A. Clifford, and I. Davies. 2009. Neurophysiological evidence for categorical perception of color. Brain and Cognition 69 (2): 426-434.

Hume, D. 1748. An inquiry concerning human understanding. London: J.B. Bebbington.

Jraissati, Y. 2014a. On color categorization: Why do we name seven colors in the rainbow? Philosophy Compass 9 (6): 382-391.

Jraissati, Y. 2014b. Proving universalism wrong does not prove relativism right: Considerations on the ongoing color categorization debate. Philosophical Psychology 27 (3): 401-424.

Jraissati, Y., and I. Douven. 2017. Does optimal partitioning of color space account for universal color categorization? PLoS One 12 (6): e0178083.

Kaeppler, K., and F. Mueller. 2013. Odor classification: A review of factors influencing perception-based odor arrangements. Chemical Senses 38 (3): 189-209.

Kay, P., and C.K. McDaniel. 1978. The linguistic significance of the meanings of basic color terms. Language 54 (3): 610-646.

Komarova, N.L., K.A. Jameson, and L. Narens. 2007. Evolutionary models of color categorization based on discrimination. Journal of Mathematical Psychology 51: 359-382.

Koster, E.P., J. Degel, and D. Piper. 2002. Proactive and retroactive interference in implicit odor memory. Chemical Senses 27 (3): 191-206.

Köster, E. P., P. Møller, and J. Mojet. 2014. A "Misfit" Theory of Spontaneous Conscious Odor Perception (MITSCOP): reflections on the role and function of odor memory in everyday life. Frontiers in psychology 5: 64.

Kurtz, D.B., P.R. Sheehe, P.F. Kent, T.L. White, D.E. Hornung, and H.N. Wright. 2000. Odorant quality perception: A metric individual differences approach. Perception \& Psychophysics 62 (5): 1121-1129.

Lenneberg, E. 1961. Color naming, color recognition, color discrimination: a re-appraisal. Perceptual and Motor Skills 12: 375-382.

Lenneberg, E.H., and J. Roberts. 1956. The language of experience: A study in methodology. International Journal of American Linguistics, Memoir no. 13.

Levin, D.T., and M.R. Banaji. 2006. Distortions in the perceived lightness of faces: The role of race categories. Journal of Experimental Psychology: General 135 (4): 501.

Levinson, S.C., and A. Majid. 2014. Differential ineffability and the senses. Mind \& Language 29 (4): $407-$ 427.

Lewis, D. 1969. Convention. Cambridge: Harvard University Press.

Liberman, A.M., K.S. Harris, H.S. Hoffman, and B.C. Griffith. 1957. The discrimination of speech sounds within and across phoneme boundaries. Journal of Experimental Psychology 54: 358-368.

Liberman, A.M., S.C. Franklin, D.P. Shankweiler, and M. Studdert-Kennedy. 1967. Perception of the speech code. Psychological Review 74 (6): 431.

Lindemann, B., Y. Ogiwara, and Y. Ninomiya. 2002. The discovery of umami. Chemical Senses 27 (9): $843-$ 844. 
Locke, J. (1689, 2012) An essay concerning human understanding. $6^{\text {th }}$ ed. The University of Adelaide EBooks.

Lorig, T.S. 1999. On the similarity of odor and language perception. Neuroscience and Biobehavioral Reviews 23: 391-398.

Lucy, J. 1996. The scope of linguistic relativity: An analysis and review of empirical research. In Rethinking linguistic relativity, ed. J. Gumperz and S. Levinson, 37-69. Cambridge: Cambridge University Press.

Ludlow, P. 1999. Semantics, tense, and time: An essay in the metaphysics of natural language. Cambridge: MIT Press.

Maffi, L. 1990. Somali color term evolution: Grammatical and semantic evidence. Anthropological Linguistics 32 (3-4): 316-334.

Majid, A., and N. Burenhult. 2014. Odors are expressible in language, as long as you speak the right language. Cognition 130 (2): 266-270.

Malnic, B., J. Hirono, T. Sato, and L.B. Buck. 1999. Combinatorial receptor codes for odors. Cell 96 (5): $713-$ 723.

Malt, B.C., S.P. Gennari, M. Imai, E. Ameel, N. Saji, and A. Majid. 2015. Where are the concepts. In The conceptual mind: New directions in the study of concepts, ed. E. Margolis and S. Laurence. Cambridge: MIT Press.

Markie, P. 2017. Rationalism vs. Empiricism. The Stanford Encyclopedia of Philosophy (Fall 2017 Edition), ed Edward N. Zalta. URL $=<$ https://plato.stanford.edu/archives $/$ fall $2017 / \mathrm{entries} / \mathrm{rationalism}$ empiricism/>.

Melville, H. 1851. Moby-dick or the whale. New York: Harper \& Brothers Publishers.

Mitterer, H., J. Horschig, J. Musseler, and A. Majid. 2009. The influence of memory on perception: It's not what things look like, it's what you call them. Journal of Experimental Psychology 35 (6): 1557-1562.

Montemayor. 2019. Early and late time perception: On the narrow scope of the Whorfian hypothesis. Review of Philosophy and Psychology 10 (1): 133-154.

Mouélé, M. 1997. L'apprentissage des odeurs chez les Waanzi. Enfance 50 (1): 209-222.

Noble, A.C., R.A. Arnold, B.M. Masuda, S.D. Pecore, J.O. Schmidt, and P.M. Stern. 1984. Progress towards a standardized system of wine aroma terminology. American Journal of Enology and Viticulture 35 (2): $107-109$.

O'Mahony, M., and R. Ishii. 1986. A comparison of English and Japanese taste languages: Taste descriptive methodology, codability and the umami taste. British Journal of Psychology 77 (2): 161-174.

Olofsson, J.K., and J.A. Gottfried. 2015. The muted sense: Neurocognitive limitations of olfactory language. Trends in Cognitive Sciences 19 (6): 314-321.

Olofsson, J.K., and D. Wilson. 2018. Human olfaction: It takes two villages. Current Biology 28 (3): R108R110.

Park, J., S. Tauber, K.A. Jameson, and L. Narens. 2018. The evolution of shared concepts in changing populations. The Review of Philosophy and Psychology. https://doi.org/10.1007/s13164-018-0420-5 (this issue).

Picard, D., C. Dacremont, D. Valentin, and A. Giboreau. 2003. Perceptual dimensions of tactile textures. Acta Psychologica 114 (2): 165-184.

Pressnitzer, D., T.R. Agus, and C. Suied. 2013. Acoustic timbre recognition. In Encyclopedia of computational neuroscience, ed. D. Jaeger and R. Jung. Berlin Heidelberg: Springer Reference, Springer-Verlag.

Prychitko, E. 2018. Dissociating the Cognitive Penetrability of Perception and the Theory-Ladenness of Observation. Paper presented in Turin, "Cognitive penetration" conference.

Pullum, G. 1991. The great Eskimo vocabulary hoax and other irreverent essays on the study of language. The University of Chicago Press.

Pylyshyn, Z.W. 1999. Is vision continuous with cognition? The case for cognitive impenetrability of visual perception. Behavioral and Brain Sciences 22: 341-364.

Raftopoulos, A. 2001. Is perception informationally encapsulated? The issue of the theory-ladenness of perception. Cognitive Science 25: 423-451.

Raftopoulos, A. 2017. Pre-cueing, the epistemic role of early vision, and the cognitive impenetrability of early vision. Frontiers in Psychology 8: 1156.

Regier, T., P. Kay, and R.S. Cook. 2005. Focal colors are universal after all. Proceedings of the National Academy of Sciences 102 (23): 8386-8391.

Regier, T., P. Kay, and N. Khetarpal. 2007. Color naming reflects optimal partitions of color space. PNAS 104 (4): 1436-1441.

Regier, T., A. Carstensen, and C. Kemp. 2016. Languages support efficient communication about the environment: Words for snow revisited. PLoS One 11 (4): e0151138. 
Rivers, W.H.R. 1901. In Reports on the Cambridge anthropological expedition to the Torres Straits, ed. A.C. Haddon. London: Cambridge University Press.

Roberson, D., and J. Davidoff. 2000. The categorical perception of colours and facial expressions: The effect of verbal interference. Memory \& Cognition 28: 977-986.

Roberson, D., I. Davies, and J. Davidoff. 2000. Color categories are not universal : Replications and new evidence from a stone-age culture. Journal of Experimental Psychology: General 129 (3): 369-398.

Roberson, D., H. Pak, and J.R. Hanley. 2008. Categorical perception of colour in the left and right visual field is verbally mediated: Evidence from Korean. Cognition 107 (2): 752-762.

Rosch, E.H. 1973. Natural categories. Cognitive Psychology 4: 328-350.

Rosch, E. 1999. In Concepts core readings, ed. E. Margolis and S. Laurence. Cambridge: MIT Press.

Sapir, E. 1929. The status of linguistics as a science. Language 5: 207-214.

Shepard, G.H. 1992. Pharmacognosy and the senses in two Amazonian societies (Master's Thesis). Berkeley: University of California.

Shepherd, G. 2004. The human sense of smell: Are we better than we think? PLoS Biology 2 (5): 0572-0575.

Siok, W.T., P. Kay, S.Y.W. Wang, A.H.D. Chan, L. Chen, K.K. Luke, and L.H. Tan. 2009. Language regions of brain are operative in color perception. PNAS 106: 8140-8145.

Siuda-Krzywicka, K., Boros, M., Bartolomeo, P., and C. Witzel. 2019, in press. The biological bases of colour categorisation: from goldfish to the human brain. Cortex.

Smith, E.E. 1989. Three distinctions about concepts and categorization. Language and Mind 4 (1-2): 57-61.

Smith, E.E., and D.L. Medin. 1981. Categories and concepts. Cambridge: Harvard University Press.

Solomon, G.E.A. 1990. Psychology of novice and expert wine talk. The American Journal of Psychology: 495-517.

Soufflet, I., M. Calonnier, and C. Dacremont. 2004. A comparison between industrial experts' and novices' haptic perceptual organization: A tool to identify descriptors of the handle of fabrics. Food Quality and Preference 15 (7-8): 689-699.

Sperber, D. 1975. Rethinking symbolism. Cambridge: Cambridge University Press.

Steels, L., and T. Belpaeme. 2005. Coordinating perceptually grounded categories through language. A case study for colour. Behavioral and Brain Sciences 24 (8): 469-529.

Thierry, G., P. Athanasopoulos, A. Wiggett, B. Dering, and J.R. Kuipers. 2009. Unconscious effects of language-specific terminology on preattentive color perception. Proceedings of the National Academy of Sciences 106 (11): 4567-4570.

Travers, E., Fairhurst, M.T., and O. Deroy (unpublished). Racial biases in social perception: Fast, unconscious, but still surmountable. https://psyarxiv.com/je7j4/

Walla, P., B. Hufnagl, J. Lehrner, D. Mayer, G. Lindinger, H. Imhof, et al. 2003. Olfaction and depth of word processing: A magnetoencephalographic study. Neuroimage 18 (1): 104-116.

Wawrzyniak, S. 2016. Words for odours: Language skills and cultural insights. In, ed. M. Barkat-Defradas and E. Motte-Florac. Newcastle upon Tyne: Cambridge Scholars Publishing.

Whorf, B.-L. 1940. Science and linguistics. Technological review 42 (6): 229-231-247-248.

Whorf, B.-L. 1956. In Language, thought and reality: Selected writings, ed. J.B. Caroll. New York: Wiley.

Winawer, J., N. Witthoft, M.C. Frank, L. Wu, A.R. Wade, and L. Boroditsky. 2007. Russian blues reveal effects of language on color discrimination. PNAS 104: 7780-7785.

Witzel, C. 2018. Misconceptions about colour categories. Review of Philosophy and Psychology. https://doi. org/10.1007/s13164-018-0404-5 (this issue).

Witzel, C., and K.R. Gegenfurtner. 2013. Categorical sensitivity to color differences. Journal of Vision 13 (7).

Witzel, C., and K.R. Gegenfurtner. 2015. Categorical facilitation with equally discriminable colors. Journal of Vision 15 (8): 22.

Witzel, C., and K.R. Gegenfurtner. 2018. Are red, yellow, green, and blue perceptual categories? Vision Research 151: 152-163.

Wnuk, E., and A. Majid. 2014. Revisiting the limits of language: The odor lexicon of Maniq. Cognition 131 (1): 125-138.

Yeshurun, Y., and N. Sobel. 2010. An odor is not worth a thousand words: From multidimensional odors to unidimensional odor objects. Annual Review of Psychology 61 (1): 219-241.

Yoshida, M. 1968. Dimensions of tactual impressions. Japanese Psychological Research 10: 157-173.

Publisher's Note Springer Nature remains neutral with regard to jurisdictional claims in published maps and institutional affiliations. 